\title{
Modelagem dos padrões da expansão urbana da Região Metropolitana de São Paulo baseada em Autômatos Celulares
}

\author{
Modeling Urban Sprawl Patterns of the Metropolitan \\ Region of São Paulo based on Cellular Automata
}

José Augusto Rodrigues Massabki, Anna Silvia Palcheco Peixoto, Ilza Machado Kaiser, Gustavo Garcia Manzato

\section{Resumo}

O objetivo deste trabalho foi modelar os padrões da expansão urbana da Região Metropolitana de São Paulo (RMSP) por meio da modelagem espacial, baseando-se em autômatos celulares (CA, do inglês: Cellular Automata). Para tanto foram utilizados dados do perímetro urbano referentes aos períodos de 1881, 1905, 1929, 1949, 1974 e 2005 para a construção de quatro modelos de expansão urbana. Esses modelos levam em consideração a combinação de variáveis as quais representam o estado inicial da célula (urbana ou não urbana), o número de células vizinhas classificadas como urbanas e o número de células vizinhas classificadas como não urbanas. Um modelo em particular, cuja configuração considera a combinação do estado inicial da célula com o número de células vizinhas classificadas como urbanas, apresentou o melhor desempenho (isto é, 94\% de acertos). Na sequência, uma previsão de ocupação do território para 2030 foi avaliada por esse modelo, destacando-se tanto padrões de expansão urbana orientados por infraestruturas, como processos de ocupação urbana em áreas impróprias. Em síntese, esse estudo demonstrou que a metodologia empregada pode servir como ferramenta nos processos de planejamento urbano.

Palavras-chave: Expansão urbana. Modelagem espacial. Autômatos celulares.

JARM é Professor de ensino técnico e superior, Mestrando em Engenharia Civil e Ambiental, e-mail: gutomassabki@hotmail.com ASPP é Professora, Doutora, e-mail: anna@feb.unesp.br IMK é Professora, Doutora, e-mail: ilzakaiser@feb.unesp.br GGM é Professor, Doutor, e-mail: gusmanzato@feb.unesp.br 


\section{Abstract}

The aim of this study was to model the urban sprawl patterns of the Metropolitan Region of São Paulo (MRSP) using a spatial modeling technique based on cellular automata (CA). Therefore, we used urban perimeter data related to the periods of 1881, 1905, 1929, 1949, 1974 and 2005 for the construction of four models. These models consider the combination of variables representing the initial state of the cell (urban or non-urban), the number of neighboring cells classified as urban and the number of neighboring cells classified as non-urban. $A$ particular model, whose configuration considers the combination of the initial state of the cell with the number of neighboring cells classified as urban, had the best performance (i.e., 94\% of correct predictions). Next, a land use forecast for 2030 was evaluated by this model, highlighting both infrastructure-oriented patterns of urban expansion and urban occupation processes in inappropriate areas. In summary, this study demonstrated that the method can serve as a tool in urban planning processes.

Keywords: Urban sprawl. Spatial modeling. Cellular automata.

\section{Introdução}

A expansão urbana tem se tornado uma notável característica do desenvolvimento urbano em torno do mundo nas últimas décadas (Shahraki et al., 2011). Atualmente, de acordo com as Nações Unidas (UN, 2015), 54\% da população mundial vive em áreas urbanas e está previsto que esse número deva chegar a $66 \%$ em 2050. No Brasil, de acordo com o Instituto Brasileiro de Geografia e Estatística (IBGE), a taxa de urbanização em 2010 foi aproximadamente igual a $84 \%$ e, especificamente na região sudeste do país, cerca de $93 \%$. Ou seja, como discutido por Kourtit \& Nijkamp (2013), o nosso mundo se tornou um "mundo urbano". Consequentemente, são esperadas profundas mudanças, tanto no tamanho, quanto na distribuição espacial da população global.

A Revolução Industrial foi um marco a partir da qual se observou uma acentuada migração das pessoas para as cidades em busca de trabalho e também motivadas pela procura de melhores condições de vida (Rodríguez-Pose \& Ketterer, 2012). De fato, as cidades concentram a maioria das atividades econômicas e possuem as melhores redes de infraestrutura (transportes, telecomunicações, energia elétrica, saúde, educação, lazer, etc.). Isso oferece grandes oportunidades para o desenvolvimento urbano, porém provoca uma enorme pressão nessas áreas, uma vez que são centros de atividades humanas com interações sociais e ambientais bastante intensas (Kourtit \& Nijkamp, 2013). Assim, diversas consequências negativas estão associadas aos grandes centros urbanos, como desconforto térmico, poluição atmosférica, poluição de recursos hídricos, alteração do ciclo hidrológico, deficiente provimento de saneamento básico, frequentes inundações, processos erosivos e escorregamento de taludes, além dos aspectos sociais como falta de atendimento de qualidade nos serviços de educação, saúde, transporte, baixa oferta de emprego e precárias condições de moradia.

Dessa maneira, o grande desafio para proporcionar à população dos centros urbanos melhores condições e qualidade de vida é conseguir realizar o processo de urbanização de forma organizada e planejada. Teza \& Baptista (2005) afirmam que os grandes centros mundiais atualmente sofrem as consequências de seu mau planejamento urbano, de seu deficiente ordenamento territorial e de seu errôneo modelo de desenvolvimento. Deep \& Saklani (2014) concordam com esses argumentos e acrescentam que a expansão urbana deve ser monitorada na tentativa de se projetar um habitat urbano sustentável. Além disso, Kourtit et al. (2015) sugerem que o maior desafio não é interromper o processo de urbanização ou a migração das pessoas, mas sim saber gerenciá-los e governá-los por meio de uma constante e contínua tarefa de antecipar as possíveis mudanças nas circunstâncias correntes.

Nesse sentido, a utilização de geotecnologias (sensoriamento remoto, sistemas de informação geográfica, etc.) e técnicas de análise espacial, como a modelagem espacial, auxilia o monitoramento da expansão urbana e pode fundamentar as decisões de gestão urbana, proporcionando o desenvolvimento sustentável das cidades por meio das políticas de planejamento urbano. Importante ressaltar 
que o emprego desses recursos vem se expandindo nos últimos tempos. Dentro dessa área de estudo, apesar da reconhecida complexidade na dinâmica dos processos de mudança dos usos do solo e expansão do perímetro urbano relacionados tanto com o sistema natural quanto o antrópico, a modelagem espacial por meio de Autômatos Celulares (CA, do inglês: Cellular Automata) tem proporcionado bons resultados na previsão de cenários (Almeida et al., 2005; Xiao et al., 2006; Manzato \& Rodrigues da Silva, 2010; Guan et al., 2011; Ajauskas et al., 2012; Lagarias, 2012; Caneparo \& Ricobom, 2014; Osman et al., 2015).

Com base nessas informações, este estudo procurou oferecer uma contribuição para a questão da crescente urbanização do planeta. 0 enfoque foi modelar e analisar os padrões de expansão urbana por meio de dados históricos, construindo um modelo baseado em CA. Por meio dessa investigação, o objetivo foi prever ou antecipar os padrões de ocupação do território, procurando fornecer subsídios ao planejamento urbano com uma ferramenta para o desenvolvimento urbano mais sustentável. Para tanto, um estudo de caso foi desenvolvido para a Região Metropolitana de São Paulo (RMSP), utilizando dados referentes aos anos de 1881, 1905, 1929, 1949, 1974 e 2005.

Este trabalho está organizado da seguinte maneira: primeiramente estão apresentados os aspectos da metodologia aplicada, compreendendo inicialmente um breve referencial teórico acerca dos CAs. Em seguida, a modelagem desenvolvida para a RMSP é detalhada. Na sequência estão apresentados e discutidos os resultados obtidos a partir da investigação aqui conduzida, seguida das conclusões. 0 trabalho finaliza com alguns agradecimentos e com a lista de referências bibliográficas citadas.

\section{Metodologia}

A metodologia utilizada nesse artigo está subdividida em duas partes: primeiramente é apresentado um referencial teórico sobre a técnica de modelagem espacial baseada em CA que foi aqui aplicada. Em seguida, é apresentado o detalhamento dos dados utilizados e a construção dos modelos desenvolvidos para analisar a expansão urbana da RMSP.

\section{Cellular Automata (CA)}

O conceito base para a aplicação dos CAs preconiza que é possível extrair padrões regionais através do comportamento local de um reduzido número de elementos (White \& Engelen, 1993a, 1993b; Batty \& Xie, 1994; Cecchini, 1996; Batty et al., 1997; Clarke et al., 1997). Da observação desses comportamentos individuais são extraídos grupos que categorizam padrões, formas e intensidades no espaço e no tempo. A característica que torna os CAs atrativos deve-se ao fato deles possuírem um atributo de espaço (funciona em um "universo") e, embora os elementos sejam conhecidos (na medida em que são definidos pelo utilizador), o comportamento é independente.

À semelhança do mundo real, o tempo e as dinâmicas entre elementos assumem características que variam de local para local, são imprevisíveis e complexas. Do mesmo modo, em um CA, cada elemento (célula) comporta-se individualmente e os resultados são imprevisíveis, assumindo padrões diversos em um nível global. Assim, é possível simular, ao longo do tempo e no espaço, um mundo "Autômato Celular" que pretende ser o reflexo da realidade.

Os modelos de CA apresentam algumas propriedades importantes. Em geral, pelo menos cinco características constituem um modelo $\mathrm{CA}$, apresentadas a seguir (Silva; 2002):

- Geometria da rede: o território estudado é classificado totalmente em células;

- Estados: cada célula tem pelo menos um estado (por exemplo, urbano, não urbano) e o comportamento de cada célula é definido por um conjunto de regras de transição;

- Vizinhança: as relações de vizinhança têm um papel importante no CA. Conforme ocorre no mundo real, o espaço envolvente e a sua evolução ao longo do tempo explicam os comportamentos observados;

- Regras de transição: podem ser determinísticas ou estocásticas, associadas ao comportamento de cada célula e não há limite para o número de regras;

- Sequência de períodos temporais discretos: quando ativado, o CA se comporta de modo iterativo de um período temporal para o seguinte, atualizando o espaço de maneira sincrônica. 
Santos et al. (2005) discutem que é relativamente fácil generalizar essas características para o estudo urbano, visto que a geometria da rede, que se refere à sua forma e dimensão, pode ser considerada como os territórios urbanos. Também, que o estado da célula pode representar os atributos do espaço territorial, como uso do solo e densidade populacional que, por conseguinte, permite caracterizar e avaliar qualquer atributo desejado nos modelos de CA.

Com relação à vizinhança, esta se refere à própria célula e um conjunto de células adjacentes que podem interagir entre si. Os dois tipos de vizinhança mais utilizados são a de von Neumann (quando há quatro células ortogonais ao redor de uma célula central em uma grade bidimensional) e a de Moore (quando oito células formam um quadrado em torno da célula), sendo este último o utilizado neste estudo.

Finalmente, as regras de transição, que são determinadas para refletir como ocorrem os fenômenos no mundo real, podem ser interpretadas como algoritmos na simulação, ou seja, definem as condições futuras da célula especificando o seu comportamento observado no tempo (ver, por exemplo, Wolfram, 1986, 1994; Sloot et al., 2004; Batty, 2007). Há diversas abordagens com relação às regras de transição, conforme se resume a seguir:

- Determinística: abordagem tradicional dos modelos de CA, destaca-se pela sua simplicidade e por permitir a reprodução plena das suas modelagens;

- Estocástica: abordagem em que é introduzida uma perturbação aleatória com o objetivo de reproduzir aspectos não explicáveis pelos modelos;

- Obtida por redes neurais artificiais (RNAs): abordagem em que os valores dos parâmetros são determinados automaticamente a partir de treinamento da rede neural com os dados. Por um lado isso facilita a simulação, diminuindo a necessidade de dados, entretanto torna muito difícil conhecer as regras de transição adotadas. É importante observar que esta abordagem é determinística na adoção dos pesos das conexões entre os nós, porém o processo de treinamento incorpora, de alguma maneira, a distribuição estocástica dos dados.
Um dos modelos baseados em CA que se tornou bastante popular na modelagem e simulação da expansão urbana e mudanças de usos do solo é o modelo SLEUTH. As iniciais que compõem o nome desse modelo referem-se a: Slope (declividade), Land use (uso do solo), Exclusion (áreas de exclusão que não podem se desenvolver ou serem ocupadas), Urban growth (crescimento urbano), Transportation (transporte) e Hillside (encostas). Basicamente, esses aspectos compõem os dados de entrada do modelo, permitindo considerar não só as relações de vizinhança das células, mas também a influência do meio ambiente em torno da célula na determinação das regras de transição. Para mais detalhes do modelo SLEUTH, bem como referências adicionais acerca de CAs, ver Chaudhuri \& Clarke (2013).

\section{Modelagem Espacial da Expansão Urbana da Região Metropolitana de São Paulo}

A modelagem espacial da expansão urbana da RMSP foi desenvolvida com base nos dados de contorno do perímetro urbano referentes aos anos de 1881, 1905, 1929, 1949, 1974 e 2005, organizados pelo Lincoln Institute of Land Policy (Angel et al., 2010). Esses dados, inicialmente obtidos no formato de bases de dados georreferenciadas do tipo vetorial, foram rasterizados por meio da criação de um Grid (ou seja, uma grade de células de formatos regulares) utilizando o software de Sistemas de Informação Geográfica (SIG) Maptitude versão 2015. Por meio desse procedimento, definiu-se preliminarmente o tamanho das células com medidas de 1000 por 1000 metros, obtendo-se um Grid com 23.690 células, abrangendo a área de estudo. Tal escolha é justificada pelo tempo de processamento necessário e qualidade do resultado desejado, podendo ser ajustado posteriormente para grids menores, caso os ganhos de qualidade justifiquem o esforço computacional envolvido.

Baseando-se nos dados de contorno do perímetro urbano de cada período, as células internas e/ ou interceptadas pelo contorno receberam a identificação "Urbano" e, as demais, "Não Urbano". Desta maneira, ficou definida a variável básica dos modelos, referida ao "Estado" de cada célula. A Figura 1 ilustra esse procedimento para cada um dos períodos aqui analisados. A preparação dos dados para 
aplicação da modelagem baseada em CA, envolveu a geração de duas variáveis adicionais: o "Número de Vizinhos Urbanos" e o "Número de Vizinhos Não Urbanos". Essas variáveis foram computadas para cada célula compreendida no Grid. A partir da combinação dessas três variáveis, foi possível a elaboração de quatro modelos para a análise da expansão urbana da RMSP, conforme Tabela 1.
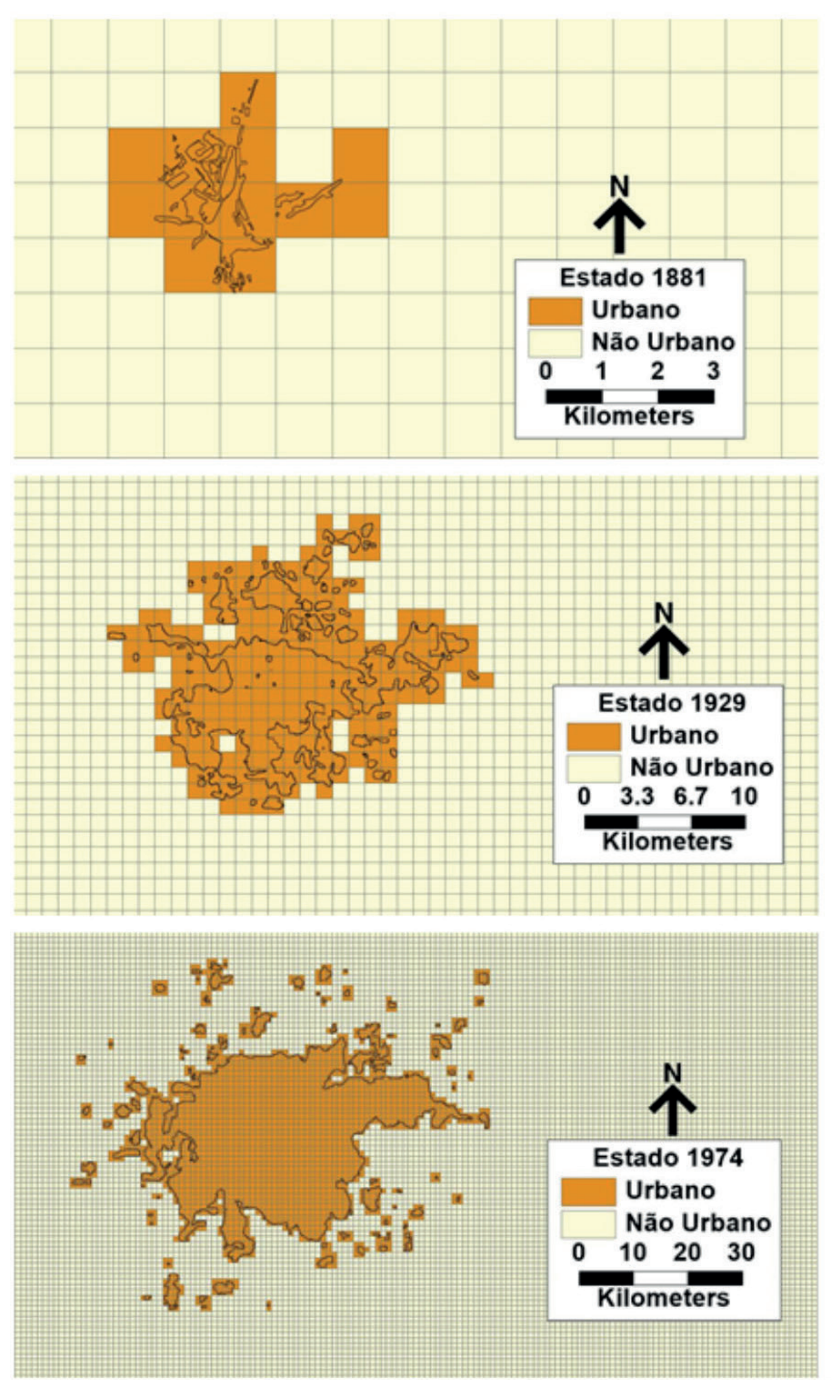

Tabela 1 - Estrutura dos modelos desenvolvidos

\begin{tabular}{cc}
\hline Modelos & Variáveis consideradas \\
\hline A & Estado, Número de Vizinhos Urbanos e Número de Vizinhos Não \\
B & Urbanos \\
C & Estado, Número de Vizinhos Não Urbanos \\
D & Estado, Número de Vizinhos Urbanos \\
\hline
\end{tabular}

Fonte: elaborado pelos autores.
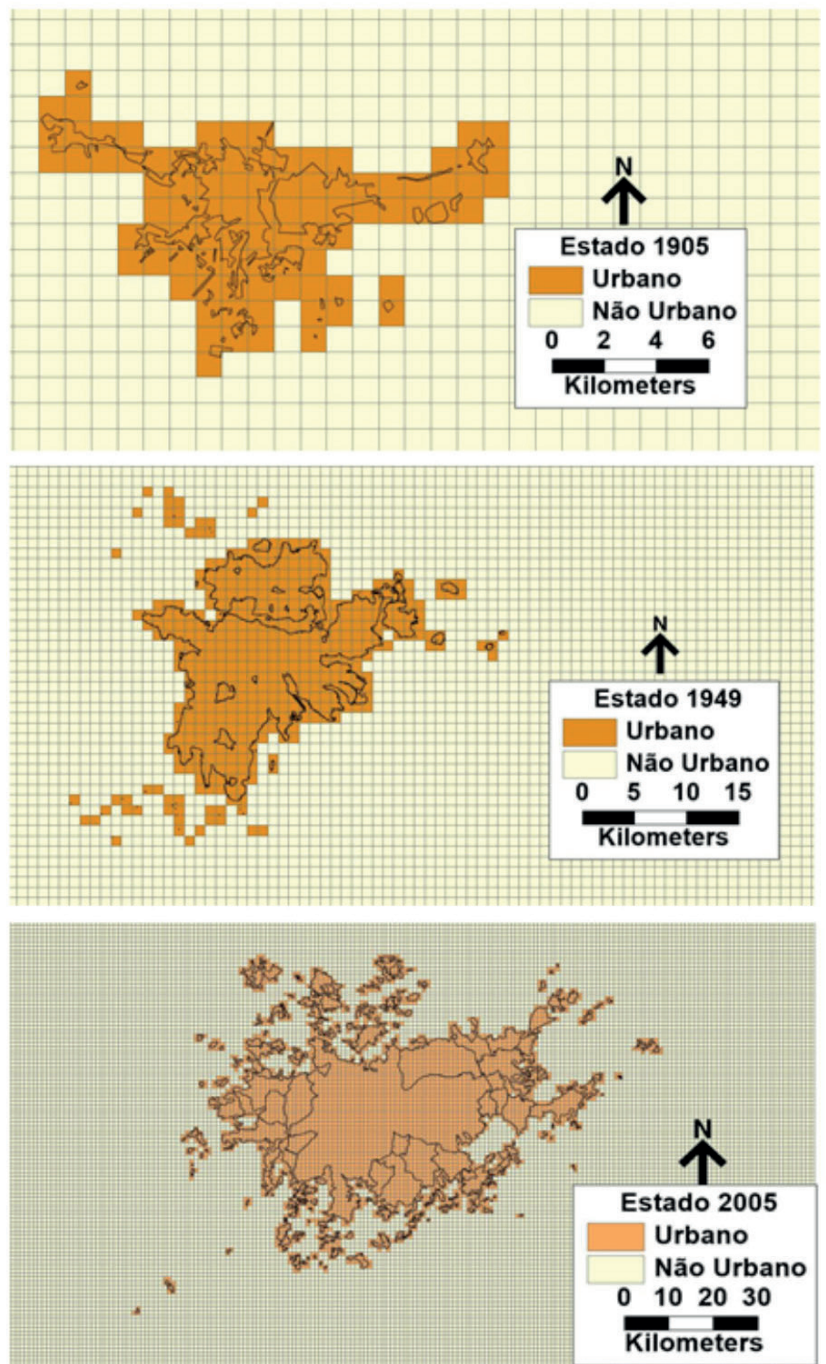

Figura 1 - Rasterização dos contornos do perímetro urbano para os períodos de 1881, 1905, 1929, 1949, 1974 e 2005. Fonte: elaborado pelos autores.

Conforme discutido, uma das características da modelagem baseada em CAs é o estabelecimento de regras de transição. Neste estudo, as regras de transição foram obtidas por meio de Redes Neurais Artificiais (RNA) com auxílio do software
EasyNN. Alguns estudos (ver, por exemplo, Ramos \& Rodrigues da Silva, 2007) mostram que o desempenho dos modelos desenvolvidos com base em RNAs é superior ao obtido com outras abordagens. 
Considerando o conjunto de dados disponíveis em diferentes períodos, uma estrutura de modelagem foi adotada baseando-se em uma adaptação dos modelos desenvolvidos por Manzato \& Rodrigues da Silva (2010). Essa estrutura de modelagem considera quatro períodos de entrada (IN) e um período de saída (OUT). Daí a denominação desse modelo como Modelo "4 IN 1 OUT". A Figura 2 ilustra a estrutura desse modelo.

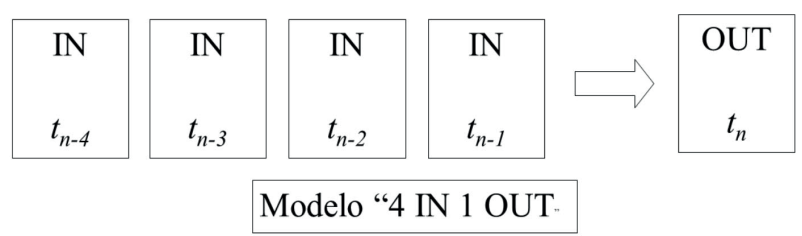

Figura 2 - Estrutura do Modelo "4 IN 1 OUT" para criação das regras de transição.

Fonte: elaborado pelos autores.

A justificativa para essa estrutura reside no fato de que o processo de modelagem por RNAs requer pelo menos duas fases principais: uma de treinamento e outra de avaliação. Adicionalmente, é possível ainda desenvolver uma terceira fase denominada previsão. Os detalhes de cada uma dessas fases são descritos a seguir. Para a realização do treinamento das RNA, foram utilizados como dados de entrada ("IN") os anos de 1881, 1905, 1929, 1949 e, como dado de saída ("OUT"), o ano de 1974. Conforme exigido para essa fase, é necessário separar o conjunto dos dados (ou seja, as 23.690 células) em duas amostras: uma de treinamento e uma de validação interna da RNA. No caso aqui estudado, foram utilizados $70 \%$ dos dados como treinamento e 30\% como validação interna. As RNAs foram construídas com uma camada intermediária e o número de neurônios nesta camada (gerado automaticamente pelo EasyNN) foi igual a 7 para o modelo A, 5 para os modelos B e C, e 3 para o modelo D. Os parâmetros inerentes à aplicação da RNA (isto é, a taxa de aprendizagem e o momentum) foram obtidos automaticamente por meio do software EasyNN, que fornece valores otimizados em cada caso. Além disso, a função de ativação empregada por esse software é do tipo sigmoidal (mais informações sobre esses parâmetros podem ser obtidas em Rodrigues da Silva et al., 2004).
A fase de avaliação refere-se à verificação do desempenho dos modelos desenvolvidos e já treinados. Para tanto, foram aplicados os dados de 1905, 1929, 1949, 1974 como entrada ("IN") resultando como dado de saída ("OUT") o ano de 2005, o qual serve de referência para a avaliação dos modelos. 0 desempenho de cada modelo foi definido pela avaliação da variável "Estado", calculando-se a porcentagem de acertos de células estimadas como "urbanas" ou "não urbanas" segundo cada modelo para 2005, comparadas à situação real em 2005. É importante destacar que as variáveis de entrada estão relacionadas àquelas apresentadas na Tabela 1 seguindo a estrutura dos modelos. Como dado de saída, considerou-se apenas a variável "Estado" (sendo o Estado em 1974 para a fase de treinamento e o Estado em 2005 para a fase de avaliação).

A fase de previsão permite projetar o cenário da expansão urbana para um período futuro. No caso aqui estudado, esse período correspondeu ao ano de 2030. Cabe ressaltar que a especificação deste ano de 2030 relaciona-se com o intervalo médio de tempo entre os períodos utilizados na modelagem, que é de aproximadamente 25 anos. Nesse caso, foram utilizados como dados de entrada ("IN") os anos de 1929, 1949, 1974, 2005 e, como dado de saída ("OUT"), o ano de 2030. A Tabela 2 resume as fases descritas juntamente com os respectivos períodos considerados.

Tabela 2 - Fases da modelagem e períodos utilizados

\begin{tabular}{cccccc}
\hline Fases & $\begin{array}{c}\text { IN } \\
\text { tn-4 }\end{array}$ & $\begin{array}{c}\text { IN } \\
\text { tn-3 }\end{array}$ & $\begin{array}{c}\text { IN } \\
\text { tn-2 }\end{array}$ & $\begin{array}{c}\text { IN } \\
\text { tn-1 }\end{array}$ & $\begin{array}{c}\text { OUT } \\
\mathbf{t}\end{array}$ \\
\hline Treinamento & 1881 & 1905 & 1929 & 1949 & 1974 \\
\hline Avaliação & 1905 & 1929 & 1949 & 1974 & 2005 \\
\hline Previs̃̃o & 1929 & 1949 & 1974 & 2005 & 2030 \\
\hline
\end{tabular}

Fonte: elaborado pelos autores.

\section{Resultados}

Na Tabela 3 apresenta-se um resumo dos resultados (porcentagem de acertos) para a fase de avaliação dos modelos. 
Tabela 3 - Desempenho dos modelos

\begin{tabular}{cc}
\hline Modelos & Porcentagem de acertos \\
\hline A & $86 \%$ \\
B & $86 \%$ \\
C & $94 \%$ \\
D & $14 \%$ \\
\hline
\end{tabular}

Fonte: elaboração dos autores.

Em se tratando do desempenho de cada modelo, pode-se afirmar que o Modelo C, baseado no Estado da célula e na relação com o Número de Vizinhos Urbanos, apresentou melhor desempenho com $94 \%$ de acertos. Em seguida observam-se os resultados dos Modelos A (baseado no Estado, Número de Vizinhos Urbanos e Número de Vizinhos Não Urbanos) e B (baseado no Estado e Número de Vizinhos Não Urbanos) com o mesmo desempenho de $86 \%$ de acertos.

Cabe observar que nem sempre modelos mais complexos produzem melhores respostas. As regras de transição são determinadas por RNAs, as quais treinam e calibram as regras de transição de acordo com dados de entrada e saída disponibilizados na modelagem. Todavia, a presença de número maior de variáveis pode fazer com que a rede não consiga extrair os padrões de desenvolvimento das transições no tempo e apresente erro grande na validação dos dados e, por conseguinte, forneça previsões imprecisas. No pior caso está o Modelo D que apresentou uma porcentagem de acertos bastante baixa, ou seja, apenas $14 \%$. É interessante destacar que o fato desse modelo D apresentar um desempenho baixo era esperado, uma vez que ele não incorpora relações de vizinhança, sendo isso contrário ao que é preconizado pela modelagem baseada em CA. No entanto, esse modelo serviu como uma referência básica para avaliar o processo de modelagem ao incluir e combinar as outras variáveis (Número de Vizinhos Urbanos e Número de Vizinhos Não Urbanos) nos modelos desenvolvidos.

Considerando-se que o Modelo $\mathrm{C}$ foi o de melhor desempenho, as análises subsequentes deste estudo foram desenvolvidas a partir dos seus resultados. Primeiramente, é importante analisar como tais resultados estão distribuídos espacialmente. Assim, conforme mostrado na Figura 3a, foi gerado um mapa com os Estados estimados por esse modelo representando as células classificadas como urbanas e não urbanas para 2005, comparadas com o contorno do perímetro urbanizado baseado no dado real de 2005.

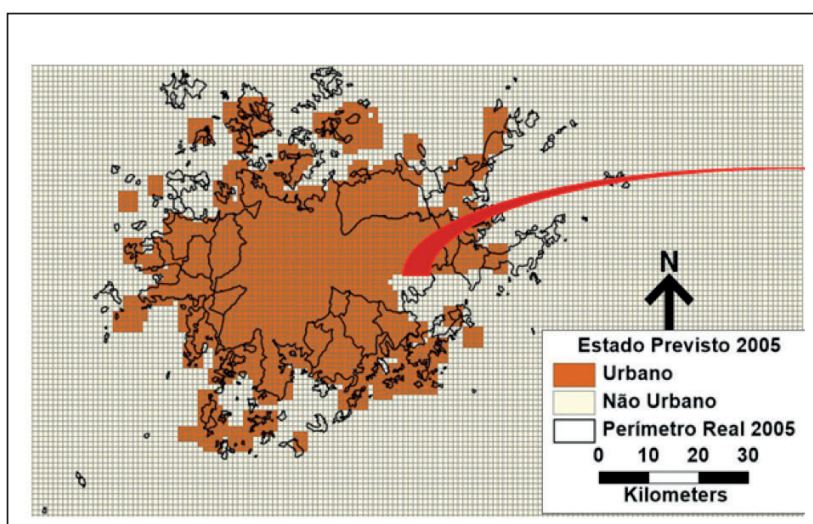

3a. Perímetro previsto $2005 \mathrm{x}$ perímetro real 2005 - fase de avaliação.

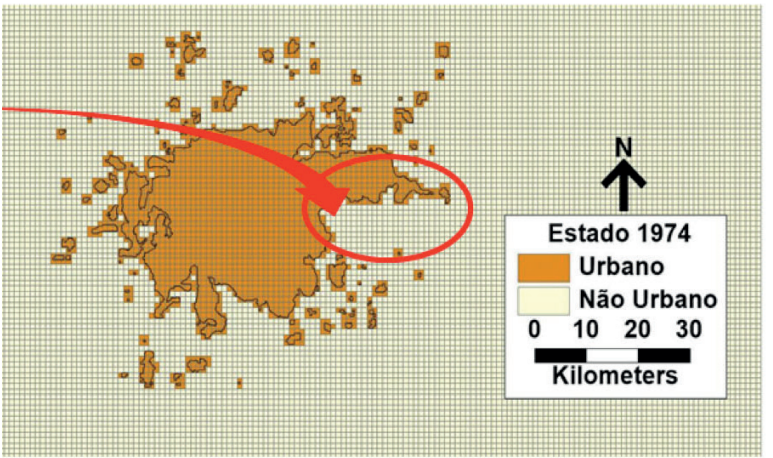

3b. Perímetro real de 1974 (utilizado como dado de saída da fase de treinamento).

Figura 3 - Estado previsto para o ano 2005 e perímetro real do ano 2005. Fonte: elaborado pelos autores. 
Percebe-se que o resultado do modelo é bastante consistente quanto à previsão dos padrões de expansão urbana. Uma observação interessante, apresentada na Figura 3, foi a não atribuição do Estado Urbano para a região centro-leste, mas apresentando um padrão linear de ocupação urbana conforme a área em destaque. Essa resposta do modelo está de acordo com os dados utilizados na fase de treinamento, visto que nesta fase foi utilizado como dado de saída do modelo o ano de 1974. Conforme ilustrado na Figura 3b, essa tendência linear de ocupação urbana ocorreu em 1974. Ou seja, o modelo foi capaz de capturar esse comportamento espacial.

Por outro lado, observando-se a Figura 3a, são verificadas algumas discrepâncias entre o Estado previsto pelo modelo e o contorno real, principalmente nas regiões de borda. Esse fato pode ser melhor visualizado por meio da Figura 4, em que foram destacadas as células cujo Estado estimado em 2005 é diferente do Estado real em 2005 (as quais correspondem aos $6 \%$ de erro do modelo C). Até um certo ponto, essas discrepâncias são esperadas, pois estão relacionadas ao processo de estabelecimento das regras de transição por meio de RNAs. Algumas formas de minimizar esses erros e aumentar o desempenho local do modelo incluem a diminuição do tamanho das células do Grid (o que aumentaria a sua "resolução") e a consideração de variáveis adicionais do meio físico, seguindo a estrutura do modelo SLEUTH (Chaudhuri \& Clarke, 2013). Embora essas abordagens não tenham sido implementadas no presente estudo, destaca-se que os resultados aqui obtidos são bastante promissores e viabilizam um aprofundamento dessas investigações.

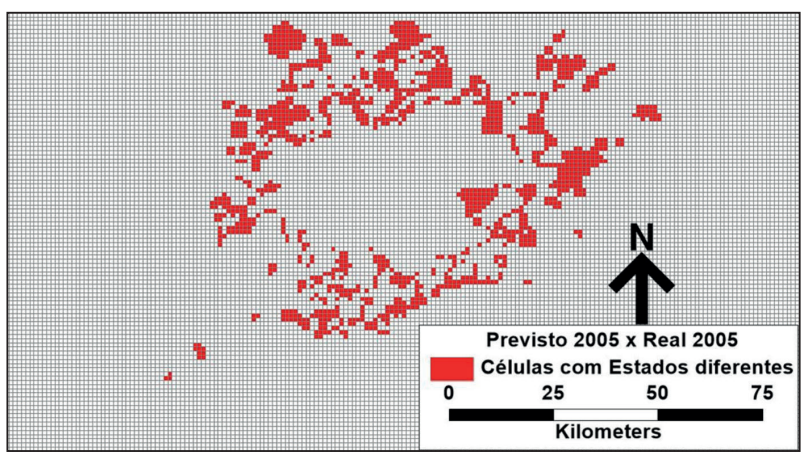

Figura 4 - Células com Estado estimado em 2005 diferente do Estado real em 2005.

Fonte: elaborado pelos autores.
Em se tratando da projeção da expansão urbana da RMSP para o ano de 2030, a Figura 5 compara os resultados previstos pelo Modelo C com a imagem de satélite obtida pelo Google Earth. Embora essa imagem seja referente ao ano de 2015 (ou seja, não corresponde ao período de projeção do modelo), ela permite destacar algumas questões pertinentes.

A primeira se refere ao fato do modelo prever um crescimento da área urbanizada no sentido da oferta de transportes, principalmente na direção das Rodovias Presidente Dutra (nordeste), e Régis Bittencourt (sudoeste). Esses destaques estão marcados em preto na Figura 5. Mesmo não se considerando a oferta de transportes no processo de modelagem aqui desenvolvido, foi possível observar que o padrão de expansão urbana apresentou uma tendência de acompanhar a disponibilidade de infraestruturas de transporte. Constatações para esse fato, ou seja, a inter-relação entre uso e ocupação do solo e transportes, podem ser encontradas abundantemente na literatura (ver, por exemplo, de la Barra, 1989; Wilson, 1998; Putman, 2007).

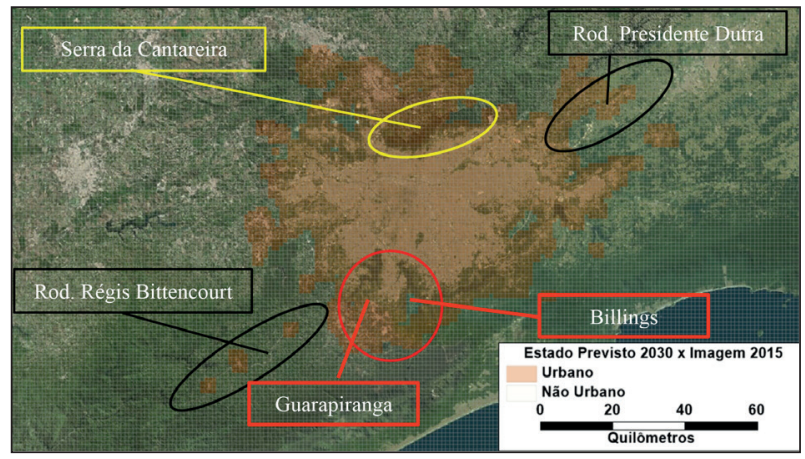

Figura 5 - Estado previsto para 0 ano de 2030 e Imagem do Google Earth referente ao ano de 2015.

Fonte: elaborado pelos autores.

Observa-se também que o modelo prevê uma expansão da ocupação urbana ao norte, sobre a Serra da Cantareira (destacado em amarelo na Figura 5). Apesar da dificuldade prática e legal de se ocupar essa região de serra (Brasil, 2012), os padrões de expansão apresentados pela modelagem podem significar um processo de sobrecarga da região, com a redução da cobertura vegetal e aumentando os impactos negativos associados à erosões e inundações de áreas urbanas. 
Por fim, ao sul da área de estudo (marcado em vermelho na Figura 5), a modelagem prevê uma expansão urbana sobre áreas de represamento de água, com destaque às Represas de Guarapiranga e Billings. Esse resultado pode indicar sobrecarga urbana sobre as áreas de reservatório, as quais requerem cuidados especiais para a conservação da cobertura vegetal em torno dos reservatórios e gestão do uso e ocupação do solo na vizinhança, garantindo a proteção desses recursos hídricos contra processos de assoreamento ou quaisquer tipos de poluição que possam afetar a qualidade das águas (Brasil, 2012).

\section{Conclusões}

O objetivo deste trabalho foi modelar os padrões da expansão urbana da Região Metropolitana de São Paulo (RMSP), por meio da modelagem espacial, baseando-se em conceitos de Cellular Automata (CA), juntamente com Redes Neurais Artificiais (RNA) para a determinação das regras de transição. Notase que a estratégia de modelagem apresentou bons resultados, tendo-se o modelo $\mathrm{C}$ (que considera o Estado e Número de Vizinhos Urbanos), em particular, com o melhor desempenho. Pela avaliação da variável "Estado", esse modelo apresentou uma porcentagem de acertos de $94 \%$ de células estimadas iguais às reais, considerando-se os dados de 2005. 0 modelo aqui desenvolvido também proporcionou resultados para uma fase de previsão, projetada para o ano de 2030. Esses resultados evidenciaram padrões de expansão urbana futuros que tendem a acompanhar as redes de infraestrutura de transportes. Além disso, os resultados dessa previsão podem fornecer subsídios à identificação de áreas mais suscetíveis de sobrecarga urbana e servir de apoio aos processos de planejamento urbano, a fim de torná-lo mais sustentável.

Em geral, embora os resultados obtidos apontem para uma viabilidade satisfatória da modelagem aqui desenvolvida, cabe destacar que o modelo ainda deve ser aprimorado. Por exemplo, ainda que o erro de 6\% para o Modelo $\mathrm{C}$ pareça pequeno, ele está localizado principalmente no limite do contorno da área urbanizada (Figura 4), ou seja, na transição entre o conjunto de células que estão classificadas como urbanas e o conjunto de células classificadas como não urbanas. Isso demonstra a possibilidade de refinamento do modelo, o que poderia ser mitigado diminuindo-se o tamanho das células do Grid.

Outro aspecto que merece ser reconsiderado refere-se às variáveis utilizadas. 0 modelo atual não apresenta condições de restrição ao processo de ocupação do território, fazendo com que áreas com reconhecido impedimento à ocupação urbana estejam livres a esse processo. Portanto, a modelagem aqui desenvolvida deve passar por esses ajustes na tentativa de incorporar tais restrições, tendo como base a reconhecida estrutura do modelo SLEUTH. Isso permite um aprofundamento nessas investigações.

Destaca-se também que este estudo foi desenvolvido considerando a expansão urbana da RMSP como um fenômeno dependente somente de seus dados históricos de perímetro urbano. Ou seja, o estudo desconsiderou a evolução das regiões vizinhas, mas isso está justificado pela ausência de tais dados do crescimento das cidades e/ou regiões vizinhas. É esperado que todo um sistema de cidades e/ou regiões adjacentes se desenvolva concomitantemente, porém em magnitudes distintas, e se juntem em um determinado período futuro. Mesmo assim, considera-se que a área de estudo aqui analisada foi significativa, uma vez que compreendeu o conjunto de municípios da RMSP, e produziu resultados bastante promissores quanto à metodologia empregada.

Em síntese, espera-se que as investigações aqui desenvolvidas contribuam para o entendimento dos processos de expansão urbana, fornecendo subsídios ao planejamento urbano com uma ferramenta para o desenvolvimento urbano mais sustentável.

\section{Agradecimentos}

Os autores agradecem às agências $\mathrm{CNPq}$ (Conselho Nacional de Desenvolvimento Científico e Tecnológico), CAPES (Coordenação de Aperfeiçoamento de Pessoal de Nível Superior) e FAPESP (Fundação de Amparo à Pesquisa do Estado de São Paulo) pelo apoio concedido em diferentes fases da pesquisa que deu origem a este trabalho. Os autores agradecem também à Caliper Corporation pela doação da licença educacional do software Maptitude utilizado neste estudo. 


\section{Referências}

Ajauskas, R., Manzato, G. G. \& Rodrigues da Silva, A. N. (2012). The definition of functional urban regions: Validation of a set of spatial models with recent census data and analysis of an additional model specification. In Proceedings of CAMUSS - International Symposium on Cellular Automata Modeling for Urban Spatial Systems (91-104). Porto, Portugal.

Almeida, C. M., Monteiro, A. M. V. \& Câmara, G. (2005). Modelos de Simulação e Prognósticos de Mudanças de Uso do Solo Urbano: Instrumento para o Subsídio de Ações e Políticas Públicas Urbanas. In Anais do XI Encontro Nacional da Associação Nacional de Pós-Graduação e Pesquisa em Planejamento Urbano e Regional - ANPUR, Salvador.

Angel, S., Parent, J., Civco, D. L. \& Blei, A. M. (2010). Atlas of Urban Expansion, Lincoln Institute of Land Policy, Cambridge, MA. Recuperado em 16 de fevereiro de 2016, de http://www.lincolninst.edu/subcenters/ atlas-urban-expansion/

Batty, M. \& Xie, Y. (1994). From cells to cities. Environment and Planning B: Planning and Design, 21, 31-48.

Batty, M., Couclelis, H., \& Eichen, M. (1997). Urban systems as cellular automata. Environment and Planning $B$ : Planning and Design, 24, 159-164.

Batty, M. (2007). Cities and complexity: understanding cities with cellular automata, agent-based models, and fractals. Cambridge: The MIT press.

Brasil (2012, 25 de maio). Lei n. 12.651, de 25 de maio de 2012. Dispõe sobre a proteção da vegetação nativa; altera as Leis n. 6.938, de 31 de agosto de 1981, 9.393, de 19 de dezembro de 1996, e 11.428, de 22 de dezembro de 2006; revoga as Leis n. 4.771, de 15 de setembro de 1965, e 7.754, de 14 de abril de 1989, e a Medida Provisória n. 2.166-67, de 24 de agosto de 2001; e dá outras providências. Recuperado em 25 de janeiro de 2017, de http:// www.planalto.gov.br/ccivil_03/_Ato2011-2014/2012/ Lei/L12651.htm

Caneparo, S. C., \& Ricobom, A. E. (2014). A cartografia prospectiva e a geração de mapas preditivos do uso e cobertura da terra - estudo de caso: perímetro urbano de Paranaguá - Paraná - Brasil. Revista Ra'e Ga, 31, 227-259.
Cecchini, A. (1996). Urban modelling by means of cellular automata: generalised urban automata with the help on-line (AUGH) model. Environment and Planning B: Planning and Design, 23, 721-732.

Chaudhuri, G. \& Clarke, K. C. (2013). The SLEUTH Land Use Change Model: A Review. The International Journal of Environmental Resources Research, 1(1), 88-104.

Clarke, K. C., Hoppen, S., \& Gaydos, L. (1997). A self-modifying cellular automaton model of historical urbanization in the San Francisco Bay area. Environment and Planning B: Planning and Design, 24, 247-261.

Deep, S. \& Saklani, A. (2014). Urban Sprawl Modeling using cellular automata. The Egyptian Journal of Remote Sensing and Space Sciences, 17, 179-187.

De la Barra, T. (1989). Integrated land use and transport modelling. Decision chains and hierarchies. (Vol. 12). Cambridge, New York: Cambridge University Press.

Guan, D., Li, H., Inohae, T., Su, E., Nagaie, T., \& Hokao, K. (2011). Modeling urban land use change by the integration of cellular automaton and Markov model. Ecological Modelling, 222, 3761-3772.

Kourtit, K. \& Nijkamp, P. (2013). In praise of megacities in a global world. Regional Science Policy and Practice, 5, 167-182.

Kourtit, K., Nijkamp, P. \& Partridge, M. D. (2015). Challenges of the New Urban World. Applied Spatial Analysis and Policy, 8(3), 199-215.

Lagarias, A. (2012). Urban sprawl simulation linking macro-scale processes to micro-dynamics through cellular automata, an application in Thessaloniki. Applied Geography 34, 146-160.

Manzato, G. G., \& Rodrigues da Silva, A. N. (2010). SpatialTemporal Combination of Variables for Monitoring Changes in Metropolitan Areas. Applied Spatial Analysis and Policy, 3, 25-44.

Osman, T., Divigalpitiya, P., \& Arima, T. (2015). Modeling urban growth scenarios in Cairo Metropolitan Region 2035. Proceedings of CUPUM, Cambridge, MA, EUA, 213-218.

Putman, S. H. (2007). Integrated Urban Models: Policy Analysis of Transportation and Land Use (RLE: The City). Vol. 1. Abingdon: Routledge. 
Ramos, R. A. R. \& Rodrigues da Silva, A. N. (2007). A spatial analysis approach for the definition of metropolitan regions - the case of Portugal, Environment and Planning B: Planning and Design, 34(1), 171-185.

Rodrigues da Silva, A. N., Ramos, R. A. R., Souza, L. C. L., Rodrigues, D. S. \& Mendes, J. F. G. (2004). SIG: Uma plataforma para introdução de técnicas emergentes no planejamento urbano, regional e de transportes. São Carlos: Edição dos autores.

Rodríguez-Pose, A. \& Ketterer, T. D. (2012). Do local amenities affect the appeal of regions in Europe for migrants? Journal of Regional Science, 52, 535-561.

Santos, V. S., Lima, R. S. \& Rodrigues da Silva, A. N. (2005). Modelagem da dinâmica populacional intra-urbana com Cellular Automata e avaliação multicritério. In A. N. Rodrigues da Silva; L. C. L. Souza \& J. F. G. Mendes (Eds.) Planejamento Urbano, Regional, Integrado e Sustentável. Desenvolvimentos recentes no Brasil e em Portugal, São Carlos: Edição dos autores.

Shahraki, S. Z., Sauri, D., Serra, P., Modugno, S., Seifolddini, F. \& Pourahmad, A. (2011). Urban sprawl pattern and land-use change detection in Yazd. Iran, Habitat International, 35, 521-528.

Silva, E. A. (2002). Cenários da Expansão Urbana na Área Metropolitana de Lisboa. Revista de Estudos Regionais, (5), 23-41.

Sloot, P. M. A., Chopard, B. \& Hoekstra, A. G. (2004). Cellular automata: 6th International Conference on Cellular Automata for Research and Industry. Berlin: Heidelberg: Springer-Verlag.

Teza, C. T. V. \& Baptista, G. M. M. (2005). Identificação do fenômeno ilhas urbanas de calor por meio de dados ASTER on demand 08 - Kinetic Temperature (III): metrópoles brasileiras. In Anais do XII Simpósio Brasileiro de Sensoriamento Remoto (p. 3911-3918), INPE, Goiânia, Brasil.
United Nations - UN. (2015). Department of Economic and Social Affairs, Population Division. World Urbanization Prospects: The 2014 Revision, (ST/ESA/SER.A/366).

White, R. \& Engelen, G. (1993a). Cellular automata and fractal urban form: a cellular modelling approach to the evolution of urban land-use patterns. Environment and Planning A, 25, 1175-1199.

White, R. \& Engelen, G. (1993b). Cellular dynamics and GIS: modelling spatial complexity. Geographical Systems, $1,237-253$

Wilson, A. G. (1998). Land-use/transport interaction models: Past and future. Journal of transport economics and policy, 32(1), 3-26.

Wolfram, S. (1986). Theory and Applications of Cellular Automata. Vol. 1. Singapore: World scientific.

Wolfram, S. (1994). Cellular automata and complexity: collected papers. Vol. 1. Reading, MA: Addison-Wesley.

Xiao, J., Shen, Y., Ge, J., Tateishi, R., Tang, C., Liang, Y. \& Huang, Z. (2006). Evaluating urban expansion and land use change in Shijiazhuang, China, by using GIS and remote sensing. Landscape and Urban Planning, 75, 69-80.

Recebido: Nov. 09, 2016

Aprovado: Mar. 08, 2017 